\title{
Inaccuracies in survey reporting of alcohol consumption
}

\author{
Conor Gilligan ${ }^{1 *} \mathbb{D}$, Kristen G. Anderson², Benjamin O. Ladd ${ }^{3}$, Yun Ming Yong ${ }^{1}$ and Michael David ${ }^{1}$
}

\begin{abstract}
Background: Alcohol consumption estimates in public health predominantly rely on self-reported survey data which is likely to underestimate consumption volume. Surveys tend to ask specifically about standard drinks and provide a definition or guide in an effort to gather accurate estimates. This study aimed to investigate whether the inclusion of the term standard drinks with pictorial guide is associated with an adjustment in self-reported alcohol volume.

Methods: A web-based survey was administered with AUDIT-C questions repeated at the beginning and end of the survey with and without the standard drink term and guide. The order in which respondents were presented with the different question types was randomised. Two cohorts of university/college students in NSW Australia $(n=$ $122)$ and the US Pacific Northwest $(n=285)$ completed the survey online.

Results: Australian students did not adjust their responses to questions with and without the standard drink term and pictorial guide. The US students were more likely to adjust their responses based on the detail of the question asked. Those US students who drank more frequently and in greater volume were less likely to adjust/apply a conversion to their consumption.

Conclusions: This study supports previous findings of the inaccuracy of alcohol consumption volume in surveys, but also demonstrates that an assumption of underestimation cannot be applied to all individual reports of consumption. Using additional questions to better understand drink types and serving sizes is a potential approach to enable accurate calculation of underestimation in survey data.
\end{abstract}

Keywords: Standard drink, Surveys, Measures, Underestimation, Alcohol

\section{Introduction}

Population-level estimates of alcohol-consumption and the level of risk associated with drinking rely on selfreported data defining consumption in terms of 'standard drinks'. The standard drink measure was conceived to standardise the volume of pure alcohol in beverages served in commercial settings, but has since been used to quantify safe or low risk drinking levels [1] and alcohol consumption data collected in surveys [2].

International variations exist in the definition of a standard drink. Individuals' understanding of, and ability to apply the concept to survey responses or self-poured servings of alcohol has been associated with an underestimation of consumption [3]. Studies consistently show

\footnotetext{
* Correspondence: Conor.Gilligan@newcastle.edu.au

${ }^{1}$ University of Newcastle, School of Medicine and Public Health, University

Drive Callaghan, Newcastle, NSW 2308, Australia

Full list of author information is available at the end of the article
}

that estimates of alcohol consumption based on selfreported surveys underestimate drinking volume, with some approaches accounting for as little as 40 to $60 \%$ of alcohol sales [4]. Other approaches, using location and beverage specific questions have been found to account for up to $94 \%$ of taxable alcohol $[5,6]$. Such underestimation has important implications for the measurement of alcohol-related risk at both individual and population levels, and the interpretation of alcohol-related burden of disease data. A review of studies using tasks such as self-pouring and image selection, reported that overestimation of standard drink size (pouring more than the volume of a standard drink) was common to participants in the US, UK, Australia, and the Netherlands, despite substantial differences in each countries' definition [3]. It follows that responses to survey questions

(C) The Author(s). 2019 Open Access This article is distributed under the terms of the Creative Commons Attribution 4.0 International License (http://creativecommons.org/licenses/by/4.0/), which permits unrestricted use, distribution, and reproduction in any medium, provided you give appropriate credit to the original author(s) and the source, provide a link to the Creative Commons license, and indicate if changes were made. The Creative Commons Public Domain Dedication waiver (http://creativecommons.org/publicdomain/zero/1.0/) applies to the data made available in this article, unless otherwise stated. 
about standard drink consumption are likely to underestimate the actual volume consumed.

Several studies have reported differences in the volume of alcohol consumption reported in response to varied question styles including quantity-frequency, graduatedfrequency, and recent recall [7-9]. While the Alcohol Use Disorders Identification Test (AUDIT-C) is a widely used and validated approach to screen for alcohol misuse [10,11], its use as an estimate of consumption volume is problematic. Quantity-frequency questions, such as the AUDIT-C, typically use the mid-point for number of drinks and number of days in each response option to generate consumption volume (e.g. assuming 2.5 days per week for the option ' 2 or 3 days per week'), and underestimate consumption compared with a question about how many drinks were consumed on the previous day $[12,13]$. In comparison to 'yesterday' methods however, quantity-frequency approaches are less likely to overestimate abstention, and have comparable criterion and predictive validity [14]. The AUDIT-C also uses a longer reference period of the last three months which is likely to be associated with greater recall bias than shorter periods such as three days or the last three or four drinking occasions $[15,16]$. Stockwell et al. suggest that underestimation in surveys can be attributed to forcing respondents to report in terms of standard drinks and on typical days, not allowing for differences on weekends or different weekdays [8]. Importantly, underestimation of consumption is reported to be greater among younger male drinkers [13, 17], middle-aged female drinkers, and those who engaged less frequently in heavy episodic drinking, and is less marked among young and older females [6]. There also appears to be differential under-reporting of beer compared to other beverages [12]. Important differences also emerge depending on the way questions and response options are presented, with respondents tending to select one of the first few visible options in cases such a drop-down menu of options [9].

Part of the explanation for variance in reporting, and for under-reporting, may be the varied drinking patterns and socio-cultural norms in different drinking contexts and subcultures. Alcohol is consumed differently in private settings relative to commercial settings and licensed premises, although this variation is likely to be more relevant to some beverage types than others [3]. For example, beer is generally consumed in fixed serving sizes (which differ within and between countries), while wine is poured to various levels in various glass sizes $[3,18]$. In licensed premises, there is little or no stipulation of the sizes or alcohol volume of beverages served. In Australia and the USA, liquor licensing requires serving staff to complete training (Responsible Service of Alcohol/ Service Permit), but the focus of training is knowledge of alcohol policies, identification of intoxicated patrons, and ensuring that intoxicated patrons are not served alcohol as opposed to 'serving' alcohol per se $[19,20]$. The variation in consumption styles reinforces the need for standardised measures to quantify consumption in surveys.

Irrespective of whether a survey question asks about consumption 'yesterday' or 'on a typical day', population-level consumption volume estimated from brief survey questions, usually relies on the assumption that respondents are reporting standard drink consumption. Given the evidence for over-estimation of standard drink size [3], this typically requires an adjustment of responses from the number of drinks or serves an individual consumes to convert into standard drinks. Many surveys present a figure including images of typical beverage types and containers, indicating the number of standard drinks in each to aide this conversion or adjustment [21, 22], but the extent to which individuals 'adjust' their answers in response is unknown. Previous studies have predominantly compared alcohol consumption estimated with different cohorts $[17,23]$ or types of questions [12] but have not specifically measured the impact of the term 'standard' drink or the inclusion of a standard drinks guide.

\section{Aims}

Here, we investigate whether the inclusion of the standard drink term and pictorial guide is associated with an adjustment in self-reported alcohol consumption among two cohorts of university/college students in New South Wales, Australia, and the US Pacific Northwest. The aims of the study were to: 1 ) establish the extent to which providing a definition of a standard drink led to within-subject differences in reporting of alcohol consumption; and 2) explore factors associated with differences in reporting of alcohol consumption. Both aims are considered from a cross-national perspective comparing samples from Australia and the USA in a convenience approach based on the researchers' institutional affiliations and access to student populations. It is reasonable to expect differences in the cultural norms between the US and Australia given different tertiary education structures, as well as drinking, secondary supply and alcohol purchase laws.

\section{Methodology}

\section{Participants - recruitment}

Participants were recruited from one university in New South Wales (NSW), Australia, one in Washington, USA, and a college in Oregon, USA (Pacific Northwest sample). Recruitment materials invited students aged 18 years and above who drink alcohol to complete an anonymous, online survey. 
In NSW, students were recruited using convenience, non-probability sampling through posts on the course management sites of courses across the university as well as through student networks such as residents groups. No compensation was offered for completion. Given the potential that content associated with alcohol consumption would be covered in some programs, participants were recruited from a range of faculties and programs. In Australia there is no legal drinking age per se, but the age for the legal purchase of alcohol is 18 years.

In Oregon, students at a small, liberal arts college were recruited via posters placed on campus and online posts. In Washington, students were recruited from two campuses of a large, public university. Students were recruited from the undergraduate psychology research pool including any student enrolled in a psychology course (not necessarily psychology majors). Students could select this study from a list and were compensated for completion via course credit. The legal drinking age in the USA is 21 years of age; however, illicit drinking is common among university students under the legal age of consumption [24].

\section{Measures}

Procedures and measures were identical for both cohorts apart from the use of country-specific standard drinks images. The survey contained three blocks of questions, with slightly different versions used in Australia and the US Pacific Northwest to account for different standard drinks definitions and drinking cultures. In Australia, the standard drink size is that which contains $10 \mathrm{~g}$ of pure alcohol, while the US equivalent is $14 \mathrm{~g}$ of pure alcohol. The first block contained three questions from the AUDIT-C (see https://www.integration.samhsa.gov/ images/res/tool_auditc.pdf for a reference guide) accompanied by an Australian Standard Drinks Guide or equivalent US image (see Fig. 1 a) and b)). The three questions were (1) "How often do you have a drink containing alcohol," (2) "How many standard drinks do you have on a typical day when drinking," and (3) "How often do you have six or more standard drinks on one occasion." A second block acted as a diffuser, and the final block utilised a modified version of the AUDIT-C (mAUDIT-C), which asked the AUDIT-C questions, but replaced the term 'standard drink' with either 'drinks' or 'serves' and removed the pictorial guide. Blocks one and three were randomised for each participant. $50.5 \%$ of respondents saw the term 'serves' and $49.5 \%$ saw the term drinks. Participants were not allowed to return to previous question blocks.

Alcohol consumption volume arising from the questions in this block was reported as an ordinal variable, with respondents reporting the number of [standard] drinks consumed on a typical day as 1 or 2,3 or 4,5 or 6,7 to 9 , or 10 or more. The mid-point of these responses was taken as the number of drinks reported $(1.5,3.5,5.5,8,12)$. We created a dichotomous variable to measure adjustment of alcohol consumption volume based on whether the number of 'standard' drinks reported was significantly different from the number reported in response to questions about drinks or serves only. This measure was used as the dependent variable in logistic regression analyses.

The second block of questions included items about self-reported drinking status (non-, occasional-, light-, party/social-, heavy-, or ex-drinker), the type of alcohol usually consumed (with ten options as well as an 'other' option provided along with locally relevant examples, e.g. ordinary [full strength] beer, low alcohol beer, wine, wine coolers, champagne or sparkling wine, alcoholic cider, alcoholic sodas, premixed spirits, spirits, liqueurs including premixed liqueurs), the places where the respondent usually drinks (In my own/spouse's/partner's home, at a friend's house, at a party at someone's house, at raves/dance parties, at restaurants/cafés, at licensed premises (e.g. pubs, clubs), at University, at my workplace, in public places (e.g. parks, beaches), in a car or other vehicle, or other), and a series of items relating to drinking intentions (thinking of all the times that you drink alcohol, how often would you drink for the following reasons ...) and alcohol-related harms (e.g., being sick after drinking, violence, unwanted sexual activity). These items were selected based on the likelihood they would be associated with reported volumes, and participants were able to select multiple options.

\section{Sample}

One hundred twenty-two participants completed the survey in NSW and 285 in the Pacific Northwest USA. The participant demographics and differences between cohorts are summarised in Table 1. A majority of participants in both cohorts identified as female, the average age was 21 (20.98; $\mathrm{SD}=3.47$; Australian sample slightly older; $p<0.001$ ), and most were in the first three to four years of an undergraduate program. The Australian sample were predominantly in the first two years of a program, while US students were more commonly in their third or fourth year $(\mathrm{p}<0.001)$. Australian students were enrolled in 23 different programs, with Electrical Engineering, Oral Health, Pharmacy, and alternate entry programs most common. US students came from 28 different programs with Civil Engineering, Computer Systems Engineering, Professional Engineering, Energy Studies, or Linguistics most common.

In both cohorts, participants most commonly referred to themselves as party/social drinkers (51.5 and $68.8 \%$ of Australian and US cohorts, respectively), or occasional 


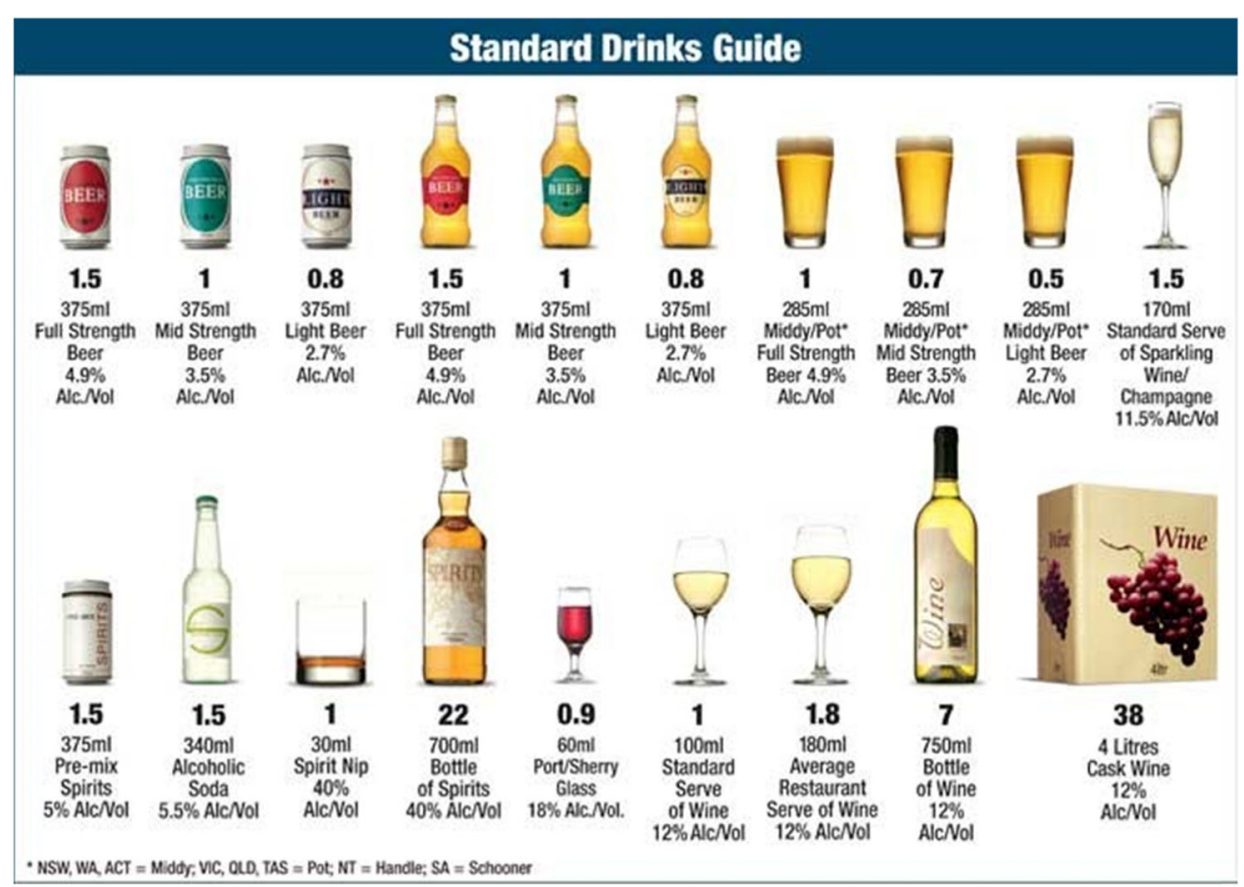

a)
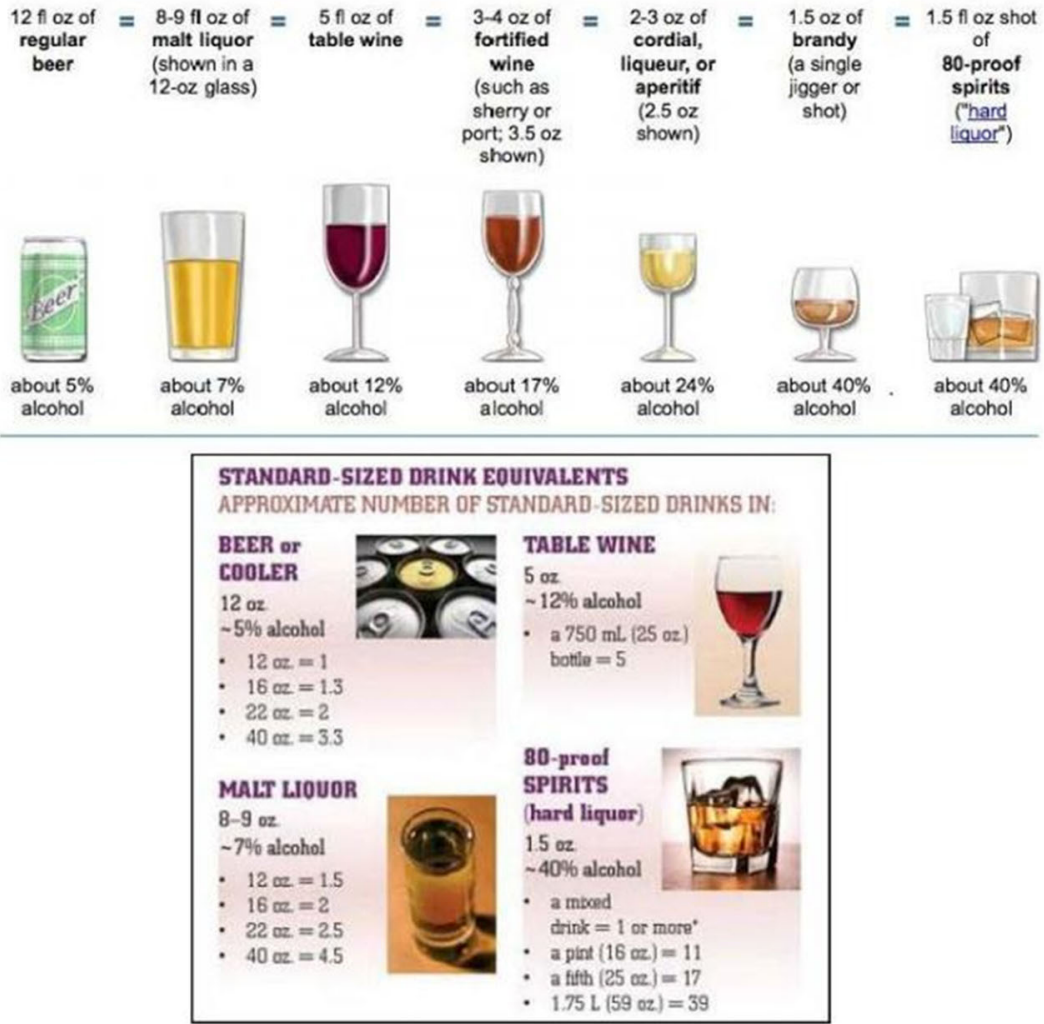

b)

Fig. 1 (See legend on next page.) 
(See figure on previous page.)

Fig. 1 a) Australian Standard Drinks Guide used in survey (Australian Government Department of Health https://www.health.gov.au/health-topics/ alcohol/). b) US Standard Drinks Guide used in survey (National Institute on Alcohol Abuse and Alcoholism https://www.rethinkingdrinking.niaaa. nih.gov/How-much-is-too-much/what-counts-as-a-drink/whats-A-Standard-drink.aspx, and Centers for Disease

Control https://www.cdc.gov/ncbddd/fasd/women.html

drinkers (33.6 and $23.5 \%$ of Australian and US cohorts, respectively). Age of initiation to drinking ranged from 9 to 21 years (mean 16.67; SD 1.82) and was not significantly different between cohorts. The types of drinks 'usually' consumed were spirits (56.0\%), full strength beer $(35.9 \%)$, wine or champagne $(50.1 \%)$, pre-mixed drinks/alcoholic sodas (34.15\%), and cider (25.1\%) with differences between the cohorts in beverage selection (see Table 1). The most commonly identified locations of drinking were home/friend's home/house party followed by licensed premises, rave parties, university, and cafes.

The average AUDIT-C score (based on the validated instrument using the standard drink term and image) was 4.53 and did not differ significantly between the groups. Forty-three percent of Australian and $44 \%$ of US respondents scored above 4 on the AUDIT-C, indicating possible hazardous drinking. In both samples, males were more likely to score above 4 than females (Australia male:female $=54.05 \%$ : 51.81\%; US male:female $=68.18 \%: 60.27 \%$ ). For a small number of women ( $n=6$ Australian and $n=4$ US), all four points were from the first question which is suggestive of lower risk drinking.

\section{Analysis}

Continuous variables were reported as mean (SD), and categorical variables as counts (\%). Continuous variables were compared by means of the two-sample Student's ttest for independent samples with equal and unequal variances (as appropriate), and ordinal variables were compared using the Pearson Chi-squared test and the Fisher's Exact test (as appropriate). Paired data were compared using the McNemar-Bowker test. Due to the cross-over design, the effects of carryover, period and sequence were assessed and found to be non-significant. The analysis of response adjustments was modelled using Firth logistic regression, without the presence of these effects. Separate models for Australian and USA students were built using a two-stage process. First, univariate analyses were performed to determine the strength of association between independent variables and adjustment of drinking volume. Independent variables included gender, age, number of standard drinks consumed on a typical drinking day, frequency of consumption, frequency of consuming more than six standard drinks, type of alcohol consumed, places where alcohol is typically consumed, alcohol-related harms and alcohol expectancies. Second, variables with a $p$-value $<$ 0.10 in the univariate analyses were included in the multivariable model. Firth's logistic regression analysis was used to overcome the computational limitations and convergence issues caused by the sparseness (separation of the data [25]). Model validity was evaluated by performing the Hosmer-Lemeshow goodness-of-fit test and the Pregibon link test [26] on each model. A $p$-value< 0.05 by the two-tailed test was considered to be statistically significant. All analyses were performed using Stata Version 15 (StataCorp LP, College Station, TX). Posthoc analysis was performed with the US sample agestratified to assess any potential differences between under-age respondents and those legally able to purchase and consume alcohol.

\section{Results}

\section{Alcohol consumption volume}

Differences in reporting of alcohol consumption associated with the presentation of the term and guide for standard drinks were assessed. In the Australian sample, participants reported consuming an average of $5.41(\mathrm{SD}=$ 3.49) 'standard' drinks on a typical drinking day, and reports for drinks and serves were $5.16(\mathrm{SD}=3.46)$ and 5.76 $(\mathrm{SD}=3.84)$ respectively. In the US sample, the reported number of standard drinks was $6.58(\mathrm{SD}=1.95)$, drinks was $4.75(\mathrm{SD}=2.13)$, and serves was $4.65(\mathrm{SD}=2.23)$. There were no statistically significant differences between reports of drinks or serves in either sample, so these were grouped in analysis. When reported standard drinks were compared with reported drinks/serves combined, there was almost no difference in the Australian sample (0.01, 95\% CI: -0.30 to $0.31, p=0.977$ ) while the values were significantly different in the US sample (1.88, 95\% CI: 1.58 to 2.17, $p<0.001$; Table 2). Differences were maintained in the US sample stratified for age $(<21$ years versus 21 and over).

\section{Alcohol consumption frequency}

Frequency of consumption differed for reports of standard drinks, and drinks/serves across the entire sample (Table 3) No significant differences were found between reports of drinks and serves, so these were grouped. For standard drinks and drinks/serves, frequency also differed between the cohorts. Australian students reported more frequent consumption of standard drinks, with fewer reporting drinking monthly or less $(25.0 \%$ vs $53.0 \%)$, and more drinking $2-4$ times per month (40.8\% 
Table 1 Characteristics of students who self-reported as drinking alcohol in the past year

\begin{tabular}{|c|c|c|c|c|}
\hline Characteristics, N (\%) or median (IQR) & Total & Australia & USA & $P$-value \\
\hline & $N=407(\%)$ & $N=122(\%)$ & $N=285(\%)$ & \\
\hline Gender $^{\mathrm{a}}$ & & & & $0.127^{j}$ \\
\hline Male & $103(25.31)$ & $37(30.33)$ & $66(23.16)$ & \\
\hline Female & $304(74.69)$ & $85(69.67)$ & $219(76.84)$ & \\
\hline Year of Program ${ }^{b}$ & & & & $<0.001^{r}$ \\
\hline 1st Year & $127(31.28)$ & $54(44.26)$ & $73(25.7)$ & \\
\hline 2nd Year & $75(18.47)$ & $30(24.59)$ & $45(15.85)$ & \\
\hline 3rd Year & $113(27.83)$ & $29(23.77)$ & $84(29.58)$ & \\
\hline 4th Year + & $91(22.41)$ & $9(7.38)$ & $82(28.87)$ & \\
\hline Program Type ${ }^{c}$ & & & & $<0.001^{k}$ \\
\hline Undergraduate & $401(98.53)$ & $116(95.08)$ & $285(100.00)$ & \\
\hline Postgraduate & $6(1.47)$ & $6(4.92)$ & $0(0.00)$ & \\
\hline Type of Drinker ${ }^{d}$ & & & & $0.005^{k}$ \\
\hline Occasional drinker & $108(26.54)$ & $41(33.61)$ & $67(23.51)$ & \\
\hline Light drinker & $29(7.13)$ & $13(10.66)$ & $16(5.61)$ & \\
\hline Party/Social drinker & $259(63.64)$ & $63(51.54)$ & $196(68.77)$ & \\
\hline Heavy drinker & $9(2.21)$ & $5(4.10)$ & $4(1.40)$ & \\
\hline Ex-drinker & $2(0.49)$ & $0(0.00)$ & $2(0.70)$ & \\
\hline $\mathrm{Age}^{\mathrm{e}}-$ mean $(\mathrm{SD})$ & $20.98(3.47)$ & $22.25(4.25)$ & $20.43(2.92)$ & $<0.001^{\prime}$ \\
\hline Age of first drink ${ }^{\mathrm{f}}-$ mean (SD) & $16.37(1.82)$ & $16.24(1.76)$ & $16.43(1.82)$ & $0.346^{1}$ \\
\hline AUDIT-C ${ }^{g}$ - mean (SD) & $4.53(2.78)$ & $4.43(2.78)$ & $4.58(2.04)$ & $0.544^{\prime}$ \\
\hline \multicolumn{5}{|l|}{ Type of drink ${ }^{h}$} \\
\hline Full strength beer & $146(35.87)$ & $38(31.15)$ & $108(37.89)$ & $0.215^{k}$ \\
\hline Low strength beer or Wine-cooler & $66(16.22)$ & $5(4.10)$ & $61(21.4)$ & $<0.001^{k}$ \\
\hline Wine & $143(35.14)$ & $61(50.00)$ & $82(28.77)$ & $<0.001^{r}$ \\
\hline Champagne & $61(14.99)$ & $27(22.13)$ & $34(11.93)$ & $0.010^{k}$ \\
\hline Cider & $102(25.06)$ & $52(42.62)$ & $50(17.54)$ & $<0.001^{k}$ \\
\hline Soda or Premix & $139(34.15)$ & $43(35.25)$ & $96(33.68)$ & $0.820^{k}$ \\
\hline Spirits & $228(56.02)$ & $63(51.64)$ & $165(57.89)$ & $0.276^{k}$ \\
\hline Liquers & $49(12.04)$ & $14(11.48)$ & $35(12.28)$ & $0.870^{k}$ \\
\hline Other & $8(91.97)$ & $3(2.46)$ & $5(1.75)$ & $0.701^{k}$ \\
\hline \multicolumn{5}{|l|}{ Location where drink consumed } \\
\hline Home & $188(46.19)$ & $188(59.84)$ & $115(40.35)$ & $<0.001^{k}$ \\
\hline Friend's place & $223(54.79)$ & $72(59.02)$ & $151(52.98)$ & $0.278^{k}$ \\
\hline House party & $247(60.69)$ & 75 (61.48) & $172(60.35)$ & $0.912^{k}$ \\
\hline Rave party & 95 (23.34) & 30 (24.59) & $65(22.81)$ & $0.703^{k}$ \\
\hline Cafe & $89(21.87)$ & $43(35.25)$ & $46(16.14)$ & $<0.001^{\prime}$ \\
\hline Licensed premises & $157(38.57)$ & 89 (72.95) & $68(23.86)$ & $<0.001^{r}$ \\
\hline University & $116(28.50)$ & $16(13.11)$ & $100(35.09)$ & $<0.001^{k}$ \\
\hline Workplace & $9(2.21)$ & $5(4.10)$ & $4(1.40)$ & $0.135^{k}$ \\
\hline Public place & $24(5.90)$ & $7(5.74)$ & $17(5.96)$ & $1.000^{k}$ \\
\hline Car & $10(2.46)$ & $2(1.64)$ & $8(2.81)$ & $0.730^{k}$ \\
\hline Other & $5(1.23)$ & $2(1.64)$ & $3(1.05)$ & $0.638^{k}$ \\
\hline
\end{tabular}

${ }^{a} \mathrm{n}($ Gender $)=407 ;{ }^{\mathrm{b}} \mathrm{n}($ Year of Program $)=406 ;{ }^{\mathrm{c}} \mathrm{n}($ Program Type $)=407 ;{ }^{\mathrm{d}} \mathrm{n}($ Type of Drinker $)=407 ;{ }^{\mathrm{e}} \mathrm{n}($ Age $)=407 ;{ }^{f} \mathrm{n}$ (Drinking Age Commencement) $=407 ;{ }^{9} \mathrm{n}($ AUDITC) $=405 ;{ }^{h} n($ Type of drink $)=407 ;{ }^{i} n$ (Location where Drink consumed $)=407$; ${ }^{j}$ Pearson's Chi-squared test; ${ }^{k}$ Fisher's exact test; 'Mann-Whitney U-test; jindependent t-test 
Table 2 Comparison between the number of standard drinks on a typical day with the number of drinks/serves for Australian and USA students

\begin{tabular}{llll}
\hline & Standard drinks & Drinks/Serves & $P$-value \\
\hline Australia $^{\mathrm{a}}$ & $5.41(3.49)$ & $5.40(3.49)$ & $0.977^{\mathrm{c}}$ \\
US $^{\mathrm{b}}$ & $6.58(1.95)$ & $4.70(2.18)$ & $<0.001^{\mathrm{c}}$ \\
US $<21$ yrs & $6.52(1.83)$ & $4.87(2.16)$ & $<0.001^{c}$ \\
US 21+ yrs & $6.66(2.13)$ & $4.44(2.19)$ & $<0.001^{c}$ \\
\hline
\end{tabular}

a 113 Australian students reported number of standard drinks and number of drinks/serves (i.e. 9 cases excluded from analysis due to one or more missing values); 285 US students ( $174<21$ years and $111>/=21$ years) reported number of stand drinks and number of drinks/serves; ${ }^{C}$ Independent t-test

vs $31.2 \%), 2$ or 3 times per week ( $25.8 \%$ vs $12.3 \%)$, and 4 or more times week ( $8.3 \%$ vs $3.5 \%)$ compared to US students. Frequency of drinking six or more standard drinks, drinks, or serves did not differ significantly between cohorts or terms (not shown). Differences in frequency reports were statistically significant when comparing standard drinks and drinks/ serves for US students $(p<0.001)$ but not for Australian students $(p=0.083)$. In the US sample, this difference was larger among students who were under 21 years of age, compared to 'of age' drinkers ( $p<0.0001$; not shown).

\section{Factors associated with lack of adjustment}

Ninety-one respondents ( $80.5 \%$ of valid responses) in the Australian sample and 63 respondents (22.1\%) in the US sample made no adjustment to their responses of typical number of drinks consumed. The difference in adjustment between age groups in the stratified US sample was not significant, though there was a trend towards smaller adjustment among those aged less than 21 (Table 2). In the Australian sample, multivariable logistic regression of factors potentially associated with a lack of adjustment found that there was no association between age, gender, number of standard drinks/drinks/serves on a typical day, frequency of drinking, or frequency of consuming six or more drinks and the probability of adjustment (Table 4). Further, none of the secondary predictors (types of drinks consumed, reasons for drinking, harms associated with drinking and the locations of drinking) were significantly associated with adjustment at the univariate level and were therefore excluded from the regression model. The model with primary predictors only was found to have good fit $(p=0.675)$ and be appropriately specified $(p=0.846)$.

In the US model (Table 4), significant overall effects were found for the number of drinks/serves/standard drinks on a typical day $(p=0.003)$ and the frequency of drinking in past 3 months $(p=0.003)$ in predicting adjustment of survey response. Those who reported drinking more in terms of both frequency and volume were less likely to adjust their consumption. Having planned to get drunk was found to have a significant positive association with the probability of adjustment $(p=0.02)$. The model had good fit $(p=0.092)$ and was appropriately specified $(p=0.365$.)

\section{Discussion}

The results suggest that Australian students in this study do not adjust/convert their survey responses to account for standard drink units. Among the US participants, however, responses differed when asked about standard drinks as opposed to drinks or serves, suggesting that adjustment was occurring to account for the standard drinks guide presented. A lack of adjustment is interpreted here as likely reflecting an underestimation of consumption, given previous evidence of overestimation of standard drink size [3]. In the absence of a gold-standard measure, however, it cannot be guaranteed that this is the case, with other possible explanations including greater consistency of reporting, greater awareness of the standard drink size, or actual serves which more closely reflect standard drink sizes among Australian respondents.

These findings are partly in keeping with previous literature from standard drink perception studies [3] and studies validating survey estimates [13]. The present study suggests that an assumption of under-estimation should not be applied to all population groups, or indeed, to entire datasets. The difference between cohorts in this study is an unexpected finding, suggesting that some cohort effects or national differences are likely to influence an individual's tendency to adjust their responses.

The adjustment performed by US students could reflect a greater understanding of the standard drink concept, possibly due to relevant learning in their programs of study or college orientation, an assumption that the 'repeated' questions warranted different responses, or a more pronounced difference between actual serving sizes and standard drinks. Alternatively, it is possible that this group had less understanding of the standard drink concept prior to study participation, hence greater adjustment upon presentation of the standard drink definition, but in that case it is difficult to speculate as to the basis of the difference between responses. While there is evidence for a lack of knowledge of the amount of alcohol contained in standard drinks [27] among the Australian population, there is a lack of evidence for the effectiveness of standard drinks guides to improve individual's knowledge and modify estimates. An Australian national survey found very poor knowledge of guidelines for lowrisk of short- and long-term harm from drinking, with less than $5 \%$ of respondents able to accurately identify the levels [23]. 
Table 3 Frequency of students having at least one standard drink/drink/serve in the past year

\begin{tabular}{|c|c|c|c|}
\hline & Standard drinks N (\%) & Drinks/Serves N (\%) & P-value \\
\hline \multicolumn{4}{|l|}{ Frequency of drinking } \\
\hline \multicolumn{4}{|l|}{ All students ${ }^{a}, \mathrm{~b}, \mathrm{c}$} \\
\hline Monthly or less & $181(44.69)$ & $71(17.75)$ & \\
\hline 2-4 times per month & $138(34.07)$ & $162(40.50)$ & \\
\hline 2or 3 times per week & $66(16.30)$ & $149(37.25)$ & \\
\hline 4+ times per week & $20(4.94)$ & $18(4.94)$ & $<0.001$ \\
\hline \multicolumn{4}{|l|}{ Australian students ${ }^{d, e, f}$} \\
\hline Monthly or less & $30(25.00)$ & $33(28.70)$ & \\
\hline 2-4 times per month & $49(40.83)$ & $41(35.65)$ & \\
\hline 2or 3 times per week & $31(25.83)$ & $34(29.57)$ & \\
\hline $4+$ times per week & $10(8.33)$ & $7(6.09)$ & 0.083 \\
\hline \multicolumn{4}{|l|}{ USA students ${ }^{\mathrm{g}, \mathrm{h}, \mathrm{i}}$} \\
\hline Monthly or less & $151(52.98)$ & $38(13.33)$ & \\
\hline 2-4 times per month & $89(31.23)$ & $121(42.46)$ & \\
\hline 2or 3 times per week & $35(12.28)$ & $115(40.35)$ & \\
\hline 4+ times per week & $10(3.51)$ & $11(3.86)$ & $<0.001$ \\
\hline
\end{tabular}

${ }^{a}$ (All students who reported drinking standard drinks) $=405 ;{ }^{b}$ (All students who reported drinking drinks or serves) $=400$;

${ }^{c} n$ (Australian students who reported drinking standard drinks and drinks or serves) $=398 ;{ }^{d} n$ (Australian students who reported drinking standard drinks) $=120$; $e_{n}$ (Australian students who reported drinking drinks or serves) $=115 ;{ }^{f} \mathrm{n}$ (Australian students who reported drinking standard drinks and drinks or serves) $=113$; ${ }^{\mathrm{g}} \mathrm{n}$ (USA students who reported drinking standard drinks) $=285 ;{ }^{\mathrm{h}} \mathrm{n}$ (USA students who reported drinking drinks or serves) $=285 ;$ i ${ }^{\mathrm{i}} \mathrm{n}$ (USA students who reported drinking standard drinks and drinks or serves $=285$; ${ }^{j}$ Stuart-Maxwell test for marginal homogeneity

The pattern of volume adjustment occurring in the US but not the Australian sample is also reflected in the frequency of drinking. It would be expected that the frequency of alcohol consumption would remain the same, regardless of adjusted volumes. This pattern could reflect a misunderstanding of the nuances between the questions. It is possible that students in the US sample interpret the question about the frequency of drinking 'standard drinks' as a question about drinking in a certain way or a certain type of drink (as displayed in the pictorial guide) rather than as the frequency of drinking per se. The interpretation of the standard drink term may differ among different population subgroups according to drinking style or age. While age-based differences were not significant in this cohort, there was a pattern in which underage US drinkers reported slightly less standard drink consumption but slightly more drink/serve consumption than their older counterparts. This supports a need to carefully interpret survey data with different sub-groups, with indications that different groups may interpret survey questions differently.

National differences might to some extent, explain the difference between the cohorts, with subtle but important variations between student subcultures. The gender imbalance was more pronounced in the US sample, with $76.8 \%$ of the US respondents identifying as female compared to $69.7 \%$ of the Australian sample. While this difference was not statistically significant, the dominance of females may have influenced the results, particularly given established differential under-reporting between age and gender groups [6]. Other important differences between the samples include age and year of study, with more US students in the third year or higher of their degree. This could be reflective of greater maturity, advanced education about the risks of drinking and standard drink guides, or of students having 'grown out' of the heavy drinking culture often associated with the early university/college years. On the other hand, Australian students had more years of drinking including years of legal drinking, thus it is possible that drinking experience accounts for higher rates of social and heavy drinking in this group. Heavy drinking cultures are often associated with freshman and early college or university years. Studies in the US have demonstrated that patterns of drinking change over the college years, with some evidence for a reduced prevalence of heavy drinking with advancing years $[28,29]$. The present data fit this pattern, with a larger proportion of underage drinkers in the US reporting consuming six or more drinks monthly or weekly $(47.1 \%)$ compared to those aged 21 and over (37.8\%).

National differences between the samples are also suggested in the variation of drink types selected. Consumption of wine, champagne, and alcoholic cider was more commonly reported by the Australian students compared to those in the US Pacific Northwest, who more 
Table 4 Multivariable Firth logistic regression analysis predicting adjustment of typical drink quantity based on survey format

\begin{tabular}{|c|c|c|c|c|c|c|c|c|}
\hline \multirow[t]{2}{*}{ Variable } & \multicolumn{4}{|c|}{ Australia } & \multicolumn{4}{|l|}{ US } \\
\hline & $\mathrm{OR}$ & $95 \% \mathrm{Cl}$ & $P$-value & Overall $p$-value & $\mathrm{OR}$ & $95 \% \mathrm{Cl}$ & $P$-value & Overall $p$-value \\
\hline Age & 0.98 & $0.86-1.13$ & 0.88 & & 1.05 & $0.95-1.15$ & 0.33 & 0.33 \\
\hline Gender (Ref: Male) & 1 & & & & 1 & & & \\
\hline Female & 0.90 & $0.22-3.70$ & 0.82 & & 0.77 & $0.39-1.53$ & 0.46 & 0.46 \\
\hline Number of drinks on a typical day (Ref: 1 or 2 ) & 1 & & & 0.46 & 1 & & & $<0.01$ \\
\hline 3 or 4 & 0.17 & $0.01-3.77$ & 0.26 & & 3.11 & $0.16-60.94$ & 0.46 & \\
\hline 5 or 6 & 0.18 & $0.01-5.18$ & 0.32 & & 13.51 & $0.71-256.61$ & 0.08 & \\
\hline 7 to 9 & 0.10 & $0-3.23$ & 0.19 & & 5.98 & $0.30-118.38$ & 0.24 & \\
\hline $10+$ & 0.91 & $0.01-72.63$ & 0.72 & & 8.03 & $0.32-202.61$ & 0.21 & \\
\hline $\begin{array}{l}\text { Frequency of drinking in the past } 3 \text { months } \\
\text { (Ref: Monthly or less) }\end{array}$ & 1 & & & 0.71 & 1 & & & $<0.01$ \\
\hline 2 to 4 times a month & 2.20 & $0.27-17.97$ & 0.46 & & 4.08 & $1.81-9.20$ & $<0.01$ & \\
\hline 2 or 3 times a week & 0.86 & $0.06-12.48$ & 0.91 & & 1.54 & $0.56-4.24$ & 0.40 & \\
\hline 4+ times a week & 0.52 & $0.01-18.01$ & 0.72 & & 3.06 & $0.71-13.14$ & 0.13 & \\
\hline $\begin{array}{l}\text { Frequency of drinking } 6+\text { drinks on one } \\
\text { occasion (Ref; Less than monthly) }\end{array}$ & 1 & & & 0.29 & 1 & & & 0.28 \\
\hline Monthly & 0.29 & $0.04-2.27$ & 0.24 & & 0.91 & $0.40-2.07$ & 0.83 & \\
\hline Weekly & 1.27 & $0.07-24.54$ & 0.87 & & 2.27 & $0.69-7.44$ & 0.18 & \\
\hline Daily or almost daily & 0.25 & $0-30.14$ & 0.57 & & 0.71 & $0.02-28.70$ & 0.86 & \\
\hline $\begin{array}{l}\text { In the past } 12 \text { months planned to get } \\
\text { drunk before drinking (Ref: Never) }\end{array}$ & & & & & 1 & & & 0.02 \\
\hline Once & & & & & 0.10 & $0.01-0.57$ & 0.01 & \\
\hline Twice & & & & & 0.54 & $0.13-2.31$ & 0.41 & \\
\hline $3-5$ times & & & & & 0.19 & $0.06-0.62$ & 0.01 & \\
\hline 5-11 times & & & & & 0.14 & $0.04-0.49$ & $<0.01$ & \\
\hline $12+$ times & & & & & 0.21 & $0.06-0.71$ & 0.01 & \\
\hline
\end{tabular}

commonly reported drinking low strength beer or wine coolers. Further, the locations of consumption differed with more Australian students reporting drinking at home, in cafes, or in licensed premises. The latter is likely to be a product of the fact that in the US, students are not legally allowed to drink alcohol until the age of 21 , and therefore are less likely to drink in public settings. Previous studies have investigated the volume of alcohol consumed in an individual serving in different settings, with wine served and poured by women in both public and private settings likely to be in excess of a standard drink [18], while serves of beer or fortified wine poured in private settings may be less than a standard drink $[18,30]$.

In the US sample, adjustment appears to occur less frequently at higher levels of drinking. This is consistent with findings that heavy drinkers may underreport their alcohol use to a greater extent than lighter drinkers [31] and is in keeping with Australian findings suggesting that high risk drinkers are less likely to accurately estimate low risk drinking levels
[32]. In contrast, however, the same study reported that individuals who had seen a standard drinks logo were more likely to accurately estimate levels of drinking that reduce the risk of long-term harms [32], and other research has suggested that those who infrequently or never engage in heavy episodic drinking underestimate their drinking by larger proportions than those who do [6]. Therefore, some drinking experience and exposure to drinks and labelling might be expected to educate drinkers about alcohol volume.

The study was limited by a small sample of voluntary participants, dominated by females. It is not possible to estimate the recruitment rate due to the nature of recruitment, but it is expected that the response rate was low. As such, the sample may not be representative of either student population. Further, it is likely that the female dominance of the sample translates into a different pattern of beverage types, volume, and frequency. Also, the recruitment of university students, while useful in targeting a group of high-risk drinkers, may bias the 
sample towards well-educated respondents likely to be better placed than the average population to understand the standard drink concept and associated adjustments.

Answers to volume and frequency questions were non-specific to the types of alcohol and contexts in which it is consumed. Participants were able to select multiple responses to the questions about alcohol type and location. It is likely that alcohol consumed at parties is different in both type and volume to that consumed at home, a friend's house, or at a café. Further, variation exists within each beverage category. For example, the emerging popularity of craft beers which are typically high alcohol volume, and the marketing of 'healthier', 'lighter' wine options complicates the estimate of actual alcohol volume consumed. The survey did not enable the selection of these beverage alternatives specifically. Without detailed mapping of consumption according to each of these parameters, likely underestimation cannot be completely understood. While this study does not provide a representative cultural comparison between these two countries, the data offers a snapshot of survey response behaviours which warrants consideration in future studies.

Internationally, we rely on surveys to monitor trends and provide an indication of alcohol-related health risk and burden. However, while surveys might capture trends in per capita consumption they do not necessarily provide an accurate estimate of volume [33]. It will therefore be important for future monitoring by public health agencies and policy-makers to better understand the discrepancies between reported and actual consumption.

\section{Conclusions}

This study supports previous findings of underestimation of alcohol consumption volume in population surveys, but demonstrates that the underestimation assumption should not be applied consistently to all individual reports of consumption. Further detail may be required in questions about drink type and serving size to more accurately quantify consumption. Location-and beverage-specific approaches which negate the need for a standard drink guide may outperform instruments such as the AUDIT-C in estimating volume, but may be less useful for assessments of risk. Adjustments made to frequency responses indicate that the standard drink term has more implications for respondents than merely the volume of consumption and raises important questions about the interpretation of standard survey questions such as the AUDIT-C. It appears that different population groups and potentially, age-based sub-groups interpret and respond to survey questions differently. Further research should explore the differing reports of consumption associated with different age groups, beverage types and contexts of consumption, as well as differences in responses to varied questions, in order to design survey questions which more accurately capture alcohol consumption volume and frequency.

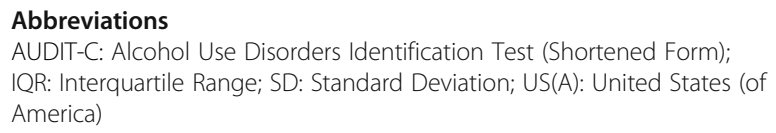

\section{Acknowledgements}

The authors wish to thank the staff who assisted with sharing the invitation to participate, and the students who participated in this study.

\section{Authors' contributions}

CG conceptualised and led the study and preparation of the manuscript, KA and BL managed the data collection in the US and contributed to interpretation of results and manuscript preparation. MY assisted with data collection in Australia and data cleaning, and MD conducted data analysis. All authors read and approved the final manuscript.

Funding

No funding was received to support this work.

\section{Availability of data and materials}

The datasets used and/or analysed during the current study are available from the corresponding author on reasonable request.

\section{Ethics approval and consent to participate}

Institutional ethics approval was obtained from the University of Newcastle Human Research Ethics Committee and exemption was granted by the Reed College Institutional Review Board and Washington State University Institutional Review Board (Office of Research Assurances). Participants were provided with information about the research at the start of the survey and completion was regarded as implied consent as was approved by the relevant committees.

\section{Consent for publication}

Not applicable.

\section{Competing interests}

The authors declare that they have no competing interests.

\section{Author details}

${ }^{1}$ University of Newcastle, School of Medicine and Public Health, University Drive Callaghan, Newcastle, NSW 2308, Australia. ${ }^{2}$ Reed College, 3203 SE Woodstock Blvd., Portland, Oregon 97202, USA. ²Department of Psychology, Washington State University, 14204 NE Salmon Creek Ave, Vancouver, WA 98686, Canada.

Received: 13 August 2019 Accepted: 21 November 2019

Published online: 05 December 2019

\section{References}

1. Cooper DB. What is a 'standard drink'? ICAP report 5. J Subst Abus. 1999; 4(2):67-9.

2. Collaborators GA. Alcohol use and burden for 195 countries and territories, 1990-2016: a systematic analysis for the global burden of disease study 2016. Lancet. 2018;392(10152):1015-35.

3. Devos-Comby L, Lange JE. "My drink is larger than yours"? A literature review of self-defined drink sizes and standard drinks. Curr Drug Abuse Rev. 2008;1(2):162-76.

4. Knibbe RA, Bloomfield K. Alcohol consumption estimates in surveys in Europe: comparability and sensitivity for gender differences. Subst Abus. 2001;22(1):23-38.

5. Casswell S, Huckle T, Pledger M. Survey data need not underestimate alcohol consumption. Alcohol Clin Exp Res. 2002;26(10):1561-7. 
6. Livingston M, Callinan S. Underreporting in alcohol surveys: whose drinking is underestimated? J Stud Alcohol Drugs. 2015;76(1):158-64.

7. Greenfield TK, Kerr WC, Bond J, Ye Y, Stockwell T. Graduated Frequencies alcohol measures for monitoring consumption patterns: Results from an Australian national survey and a US diary validity study. Contemp Drug Probl. 2009;36(3-4).

8. Stockwell T, Donath S, Cooper-Stanbury M, Chikritzhs T, Catalano P, Mateo C. Under-reporting of alcohol consumption in household surveys: a comparison of quantity-frequency, graduated-frequency and recent recall. Addiction. 2004;99(8):1024-33.

9. Dawson DA. Methodological issues in measuring alcohol use. Alcohol Res Health. 2003;27(1):18-29.

10. Dawson DA, Grant BF, Stinson FS, Zhou Y. Effectiveness of the derived alcohol use disorders identification test (AUDIT-C) in screening for alcohol use disorders and risk drinking in the US general population. Alcohol Clin Exp Res. 2005;29(5):844-54.

11. Meneses-Gaya C, Zuardi AW, Loureiro SR, Hallak JE, Trzesniak C, de Azevedo Marques JM, et al. Is the full version of the AUDIT really necessary? Study of the validity and internal construct of its abbreviated versions. Alcohol Clin Exp Res. 2010;34(8):1417-24.

12. Stockwell T, Zhao J, Chikritzhs T, Greenfield TK. What did you drink yesterday? Public health relevance of a recent recall method used in the 2004 Australian National Drug Strategy Household Survey. Addiction. 2008;103(6):919-28.

13. Stockwell T, Zhao J, Greenfield T, Li J, Livingston M, Meng Y. Estimating under- and over-reporting of drinking in national surveys of alcohol consumption: identification of consistent biases across four Englishspeaking countries. Addiction. 2016;111(7):1203-13.

14. McKenna H, Treanor C, O'Reilly D, Donnelly M. Evaluation of the psychometric properties of self-reported measures of alcohol consumption: a COSMIN systematic review. Subst Abuse Treat Prev Policy. 2018;13(1):6.

15. Cherpitel CJ, Ye Y, Stockwell T, Vallance K, Chow C. Recall bias across 7 days in self-reported alcohol consumption prior to injury among emergency department patients. Drug Alcohol Rev. 2018;37(3):382-8.

16. Lee KSK, Conigrave JH, Callinan S, Wilson S, Room R, Perry J, et al. Asking about the last four drinking occasions on a tablet computer as a way to record alcohol consumption in aboriginal and Torres Strait islander Australians: a validation. Addict Sci Clin Pract. 2019;14(1):15.

17. Stockwell T, Zhao J, Macdonald S. Who under-reports their alcoho consumption in telephone surveys and by how much? An application of the 'yesterday method' in a national Canadian substance use survey. Addiction. 2014;109(10):1657-66.

18. Banwell C. How many standard drinks are there in a glass of wine? Drug Alcohol Rev. 1999;18(1):99-101.

19. New South Wales Government, Liquor and Gaming. Responsible Service of Alcohol Training 2018 [updated 6/07/2018. NSW Government Department of Industry, Liquor and Gaming]. Available from: https://www. liquorandgaming.nsw.gov.au/Pages/liquor/serving-alcohol-responsibly/rsatraining.aspx.

20. Washington State Legislature. Washington Administrative Codes. Title 314 Chapter 314-17. Section 314-17-060. Certified October 2019. Available from: http://apps.leg.wa.gov/wac/default.aspx?cite=314-17-060

21. U.S. Department of Health and Human Services, National Institutes of Health. What is a Standard Drink? 2018 [National Institute on Alcohol Abuse and Alcoholism]. Available from: https://www.niaaa.nih.gov/alcohol-health/ overview-alcohol-consumption/what-standard-drink

22. Australian Government Department of Health. Standard drinks guide. 2010 Available from: http://www.alcohol.gov.au/internet/alcohol/publishing.nsf/ Content/drinksguide-cnt

23. Livingston M. Perceptions of low-risk drinking levels among Australians during a period of change in the official drinking guidelines. Drug Alcohol Rev. 2012;31(2):224-30.

24. Cavazos-Rehg PA, Housten AJ, Krauss MJ, Sowles SJ, Spitznagel EL, Chaloupka FJ, et al. Selected state policies and associations with alcohol use behaviors and risky driving behaviors among youth: findings from monitoring the future study. Alcohol Clin Exp Res. 2016;40(5):1030-6.

25. Heinze $G$, Schemper M. A solution to the problem of separation in logistic regression. Stat Med. 2002;21(16):2409-19.

26. Pregibon D. Goodness of link tests for generalized models. Appl Stat. 1979, 29:15-24.
27. Hasking P, Shortell C, Machalek M. University students' knowledge of alcoholic drinks and their perception of alcohol-related harm. J Drug Educ. 2005;35(2):95-109.

28. Gassman RA, Demone HW, Wechsler H. College students' drinking: master's in social work compared with undergraduate students. Health Soc Work. 2002;27(3):184-92.

29. Harford TC, Wechsler H, Seibring M. Attendance and alcohol use at parties and bars in college: a national survey of current drinkers. J Stud Alcohol. 2002;63(6):726-33.

30. Carruthers SJ, Binns CW. The standard drink and alcohol consumption. Drug Alcohol Rev. 1992:11(4):363-70.

31. Boniface S, Kneale J, Shelton N. Drinking pattern is more strongly associated with under-reporting of alcohol consumption than sociodemographic factors: evidence from a mixed-methods study. BMC Public Health. 2014;14:1297.

32. Coomber K, Jones SC, Martino F, Miller PG. Predictors of awareness of standard drink labelling and drinking guidelines to reduce negative health effects among Australian drinkers. Drug Alcohol Rev. 2017;36(2):200-9.

33. Livingston M, Callinan S, Raninen J, Pennay A, Dietze PM. Alcohol consumption trends in Australia: comparing surveys and sales-based measures. Drug Alcohol Rev. 2018;37(Suppl 1):S9-S14.

\section{Publisher's Note}

Springer Nature remains neutral with regard to jurisdictional claims in published maps and institutional affiliations.
Ready to submit your research? Choose BMC and benefit from:

- fast, convenient online submission

- thorough peer review by experienced researchers in your field

- rapid publication on acceptance

- support for research data, including large and complex data types

- gold Open Access which fosters wider collaboration and increased citations

- maximum visibility for your research: over $100 \mathrm{M}$ website views per year

At $\mathrm{BMC}$, research is always in progress.

Learn more biomedcentral.com/submissions 